\title{
Ser respetuoso es ser persona. El niño y la pedagogía moral de los nahuas del centro de México
}

\author{
Being Respectful is to be Person. \\ Children and the Moral Teaching of the Nahuas \\ from Central Mexico
}

\author{
David Lorente Fernández \\ Dirección de Etnología y Antropología Social, \\ INAH, México
}

\section{RESUMEN}

En el seno de la educación informal, la transmisión infantil del respeto resulta determinante para los indígenas nahuas del centro de México. El respeto es el valor moral principal que permite convertir a un ser humano en "persona". Sin embargo, este proceso pedagógico ha sido escasamente analizado y en gran parte continúa siendo un enigma cómo los niños adquieren lo que representa su más valiosa herramienta para conducirse adecuadamente en la vida familiar y comunitaria. Basándome en un prolongado trabajo de campo realizado en la región de la Sierra de Texcoco, cercana a la Ciudad de México, en la que los rasgos de autoascripción más convencionales, como el idioma indígena y la vestimenta tradicional, han desaparecido por los embates de los procesos de modernización, el artículo demuestra que inculcar el respeto constituye una sólida base para la conservación de la identidad étnica. Los niños son educados con relatos orales y mediante su participación en las diversas actividades cotidianas. A pesar de estar sometidos al respeto "mestizo" transmitido en el interior de las escuelas, entre los niños la moralidad nahua se impone como algo "dado" y constitutivo de la manera de ser serrana.

Palabras clave: Respeto indígena, Educación informal, Infancia, Nahuas, México.

\section{SUMMARY}

Inside informal education, the teaching of respect results decisive for Central Mexico indigenous nahua. The respect is the moral value through which a human being becomes a "person". This pedagogical process has been barely studied and has not been solved how children grabs this important tool to conduce themselves among the family and the community life. Based on an extended fieldwork performed on the Texcoco Sierra area, located close to Mexico City, in which the more common adscription features, as the indigenous language and dress has disappeared due the modernization process, this article shows that respect constitutes a solid base to preserve ethnic identity. Children are educated through oral tales and the participation on a vast array of activities on the daily life. Despite the fact to be under "mestizo" respect, which is taught on schools, the nahua morality exists among the children as "granted" and constitutes the lifestyle of the Sierra.

Key words: Indigenous Respect, Informal Education, Childhood, Nahuas, Mexico. 


\section{INTRODUCCIÓN ${ }^{1}$}

En un artículo certero, Noëlle Chamoux (1992) llamó "pedagogía indígena" al modo de transmisión de los conocimientos y los saberes técnicos propia de vastas regiones indígenas de México. Estudió esta pedagogía informal basándose en su etnografía de los nahuas de Puebla e ilustró cómo operaba en la vida cotidiana de manera abierta y asociada al ciclo vital del individuo. Demostró que los niños indígenas, y específicamente los nahuas, no se someten a instituciones educativas formales como sucede en la tradición occidental, sino que es su exposición a las situaciones sociales más diversas lo que propicia el aprendizaje. En un panorama de ausencia casi total de estudios sobre la transmisión indígena de la cultura ${ }^{2}$, su artículo constituye un buen punto de partida para abordar etnográficamente no sólo el aprendizaje de los conocimientos más teóricos y prácticos, sino del mundo de los valores, es decir, de la educación destinada a hacer de los niños "personas", sujetos con conductas socialmente apropiadas.

Pero la transformación del niño en "persona" no ha sido muy estudiada en la etnografía sobre los nahuas, a pesar de que se trata quizá de uno de los grupos mesoamericanos mejor conocidos. Las ideas indígenas son claras sobre los comportamientos legítimos o ilegítimos y, por ende, sobre cómo los niños deben conducirse. Para lograr su objetivo les inculcan "respeto", una moralidad general que se aplica a todas las situaciones y que permite juzgar las conductas, validarlas o reprobarlas; no se limita al medio familiar o social sino que involucra a la totalidad del cosmos (dioses, ancestros y hombres son, en este sentido, muy semejantes). Un niño puede ser un humano respetuoso o un individuo "ensalvajado" ${ }^{3}$ que produce graves disturbios y conflictos a todos los niveles.

En el presente artículo se explora el proceso de socialización del "respeto" en la Sierra de Texcoco, región aledaña a la Ciudad de México que posee una profunda

${ }^{1}$ El material etnográfico que sirve como sustento a este artículo fue analizado, y el artículo escrito, gracias a la beca №. 0837898 otorgada por la National Science Foundation de EE.UU. Quisiera agradecer aquí las conversaciones sostenidas con las investigadoras Barbara Rogoff y Ruth Paradise en el marco del University of California Presidential Workshop on Intent Community Participation (reuniones de 2006, 2007, 2009 y 2010). Cualquier opinión, hallazgo, conclusión o sugerencia expresada en el texto pertenece únicamente al autor y no refleja necesariamente el punto de vista de la National Science Foundation (NSF).

${ }^{2}$ Aunque mi afirmación se circunscribe al caso de México, parece constituir una situación más general según ha concluido Lourdes de León en su revisión panorámica: "la escasez de trabajos ha sido recientemente comentada por algunos autores que llaman la atención sobre el reducido número de etnografías de la infancia, el campo limitado de investigación del tema, así como la carencia de sociedades antropológicas profesionales interesadas específicamente en estas cuestiones" (De León 2005: 27). Un volumen reciente, coordinado por esta misma autora, recoge una serie de estudios clásicos sobre socialización infantil desde una perspectiva interdisciplinaria y centrada en el área americana (De León 2010). Véase Bolin (2006) para un trabajo sobre educación infantil y respeto en los Andes.

3 Empleo el término en el sentido en que lo hace Danièle Dehouve (2008), es decir, entendiéndolo como una pérdida de calidad humana en la persona al ser arrastrada por fuerzas deshumanizadoras. 
tradición histórica plasmada en su organización comunitaria y en su cosmovisión. La Sierra alberga 16.000 habitantes dedicados a la agricultura de subsistencia y al trabajo asalariado en las ciudades ${ }^{4}$ (Figura 1). Pero, como sucede en otras regiones -y esto la torna representativa y no una excepción-, la intensa modernización ha desvanecido el uso del idioma, borrado la indumentaria indígena y transformado rápidamente los rasgos identitarios convencionales 5 . Los criterios de identidad colectiva se han vuelto más sutiles. En este contexto la transmisión cultural se constituye en un mecanismo de resistencia, aunque no explícita, que permite a los serranos seguir siendo fieles a sí mismos. "Lo nahua" sobrevive a un nivel más profundo. Frente a la educación escolar los niños reciben en casa un conocimiento tradicional mientras realizan sus tareas cotidianas. Y en este aspecto nos centraremos aquí, en cómo los niños se hacen "nahuas" a pesar de la escolarización y sin necesidad de recurrir al idioma indígena. Porque la transmisión sigue otras vías: el aprendizaje moral del "respeto" por medio de relatos en castellano y del adoctrinamiento a través de los hechos, es decir, asociado a situaciones vitales concretas.

Para ilustrarlo recurriremos a la etnografía recogida durante el trabajo de campo realizado en la zona entre 2003 y 2010, que comprendió entrevistas y observación participante mientras se residía en las comunidades ${ }^{6}$; en ciertos momentos acudire-

\footnotetext{
${ }^{4}$ La Sierra de Texcoco está situada a $40 \mathrm{~km}$ al oriente de la Ciudad de México y constituye el límite entre el Valle de México y el medio poblano-tlaxcalteca. Reúne los pueblos de San Juan Totolapan, San Jerónimo Amanalco, Santa María Tecuanulco, Santa Catarina del Monte y San Pablo Ixayoc, contenidos en el triángulo formado por los cerros Tláloc, al sur, Tlamacas, al norte y Tezcutzingo al oeste. La Sierra posee una herencia chichimeca y tolteca, y su tradición cultural regional, nahua, se forjó sobre todo en el tercer reinado de Nezahualcóyotl, en 1454, cuando el rey diseñó un sistema de regadío que continúa siendo hoy el criterio esgrimido por los serranos para considerar a la zona como una región o unidad cultural. Desde la década de 1960-70 ocurrieron profundas transformaciones: el incremento de la escolaridad, la instalación del tendido eléctrico, el agua corriente, los centros de salud y el drenaje, junto a la disminución de los aspectos de la identidad indígena más visibles —el uso del idioma náhuatl (Lastra 1980) y la vestimenta tradicional-. Hoy sus habitantes se dedican principalmente al comercio de flores ornamentales, que compran en los mercados de la Ciudad de México y revenden en Texcoco o los pueblos cercanos, y a ejercer la música profesional en bandas de instrumentos de viento del ejército, la policía o las delegaciones de la capital. Otros trabajan como asalariados —albañiles, policías, asistentas domésticas- en las ciudades de México y Texcoco. También existe una agricultura de regadío y autoconsumo muy arraigada que dota de maíz, habas y frijoles a los grupos domésticos.

5 Hoy la Sierra constituye un "laboratorio sociológico", es decir, un lugar donde es posible medir el impacto de los procesos de globalización, pero también de transmisión y continuidad cultural. Pese a la creciente expansión de la Ciudad de México y la pérdida de la vestimenta y de la lengua náhuatl, la zona mantiene formas de organización comunitaria, un sistema de parentesco, ciclos festivos y una cosmovisión que revelan una ascendencia nahua directa (Lorente 2011). En este sentido es representativa de otras regiones de México — como Tlaxcala, partes de Puebla y Morelos - que conservan una herencia nahua en situaciones de cambio, de rápida pérdida de los elementos tradicionales más visibles. Véanse, respectivamente, los estudios de Hugo Nutini y Barry Isaac sobre la región de Puebla-Tlaxcala (Nutini e Isaac 1974: 432-444); el de Eileen Mulhare sobre la población que ella denomina "postnahua" de Totimehuacán, en Puebla (Mulhare 2003: 268-269), y el trabajo colectivo de Morayta, Good, Melgar, Paulo Maya y Saldaña (Morayta et al. 2003) sobre las regiones rurales de Morelos, entre otros.

${ }^{6}$ Precisando más acerca de la metodología: durante las estancias de trabajo de campo residí con varias familias. Dos de ellas tenían niños. Una era de Santa María y la otra de Santa Catarina.
} 


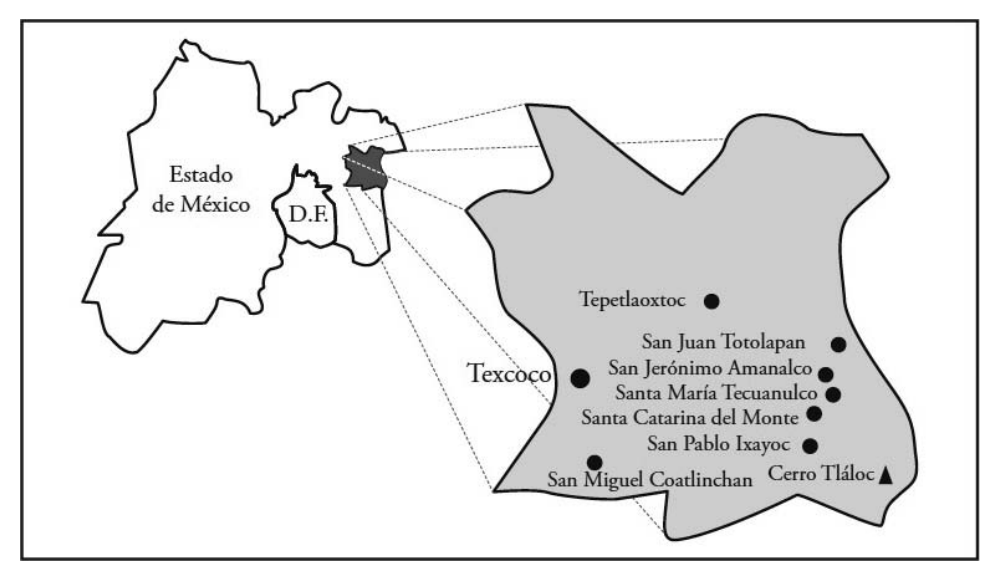

Figura 1.-La región de la Sierra de Texcoco y sus comunidades. Fuente: Lorente (2011: 64).

mos también a los datos de diferentes autores que han estudiado aspectos relacionados con el respeto en otras regiones nahuas. Atendiendo a la concepción local, consideraremos como "niño" al sujeto comprendido entre los momentos del nacimiento y el matrimonio (del recién nacido al joven de 18 ó 20 años) y describiremos la pedagogía destinada a producir niños respetuosos y evitar la aparición de infantes que persiguen únicamente su propio beneficio.

\section{LOS NIÑOS EN LA FAMILIA Y EN LA COMUNIDAD: EL CONTEXTO DE LA EDUCA- CIÓN INFORMAL}

Los niños participan intensivamente en la vida familiar y esto tiene que ver con la manera en que las familias están constituidas: puede tratarse de familias extensas si los padres viven con sus hijos y los hijos de éstos o nucleares si los hijos acaban de casarse y formar su hogar. Los niños se relacionan principalmente con los parientes pa-

\footnotetext{
Además viví de cerca la crianza de los hijos de los vecinos. Registré en el diario de campo la vida cotidiana de un pequeño de nueve y de una joven de doce, y la de un infante de cinco. Realicé entrevistas abiertas con los familiares y observé desde dentro la dinámica de los grupos domésticos y la vida íntima de las familias. Posteriormente trabajé con cuestionarios en tres escuelas primarias - dos de Santa María y una de Santa Catarina - y apliqué una encuesta de 47 preguntas sobre la relación que los niños sostenían con sus parientes corresidenciales y lejanos, sus actividades cotidianas, tipos de viviendas, ocupaciones e ingresos de los padres, empleo de la lengua náhuatl y percepción de la vida comunitaria. La muestra incluía 167 escolares, niños y niñas de entre diez y trece años, pero ofrecía información sobre una población bastante mayor, unos mil parientes. Al sistematizar el resultado surgieron patrones generalizables en toda el área y congruentes con lo que había observado en el trabajo de campo. Los testimonios que figuran en este artículo constituyen fragmentos de grabaciones o textos que los niños plasmaron por escrito en los cuestionarios. Un análisis detallado de la metodología seguida con los niños, específicamente en el contexto de la transmisión informal del sistema de creencias y la cosmología nahua, aparece en Lorente (2010: 90-92) y Lorente (2011: 199-215).
} 
ternos y aprenden que éstos residen diseminados en la comunidad por el motivo siguiente: después de la boda, y de vivir uno o dos años en casa de los padres del novio, la pareja construye una casa en un terreno heredado por el padre del marido que, según es costumbre, está muy cerca de la vivienda original. Así se forman una suerte de conjuntos de casas adyacentes adscritas territorialmente por lazos patrilineales ${ }^{7}$. Los abuelos paternos del niño, sus tíos y primos viven cerca, son sus vecinos, y en algunas ocasiones ceremoniales todos confluyen en la casa del abuelo. El niño transita de una vivienda a la otra y su existencia transcurre frecuentando varios hogares. Come por ejemplo con sus primos, duerme con sus padres, visita a sus tíos por la mañana.

La vida del niño está marcada por las "ayudas". En primer lugar debe ayudar a sus padres en las tareas domésticas aportando su trabajo (en función de la edad que posea). Los varones deben "ayudar" llevando a pastar el ganado y siguiendo al padre en las labores agrícolas y la explotación forestal. Las niñas, por su parte, participan en las tareas domésticas de cocina, limpieza y crianza de sus hermanos menores y recogen agua o lavan la ropa en los arroyos. Las nociones mismas de "ayuda" y "trabajo" entendidas como algo que los hijos hacen por los padres y su familia constituyen el núcleo central del concepto de infancia. Ser niño es una categoría relacional que se construye a lo largo del tiempo y no un vínculo consanguíneo asumido a priori. Un niño adoptado es hijo legítimo de los padres a quienes brinda su trabajo. Los padres entregan a cambio alimento, dinero, ropa, material escolar, afecto, cuidado y atenciones, y el niño se sentirá querido y aceptado por ellos ${ }^{8}$. La clasificación de los grupos de edad no es extraña a esta lógica, pues según las ayudas se designa al niño como piltziquitl (un recién nacido menor de ocho días sin bautizar), conetl (infante de ocho días), piltonconetl (el niño de entre cinco y ocho o diez años) y telpocatl o ixpocatl (el o la joven de más de diez años). A partir de ahí el muchacho es tlacamelabuac ("ya no es niño, es casado"). Estas voces no se conservan en náhuatl pero pervive el concepto en castellano?.

\footnotetext{
${ }^{7}$ Véase, sobre toda esta concepción, los estudios de Robichaux (2002: 308-309, 2005) y su modelo etnográfico del "sistema familiar mesoamericano".

${ }^{8}$ También en los pueblos de origen nahua de la vecina Tlaxcala la infancia se considera el periodo en que los bijos solteros proporcionan ayuda y trabajo a los padres de forma continuada (Magazine y Ramírez 2007). Los niños ayudan en casa casi desde el nacimiento y siguen haciéndolo hasta el matrimonio, que define su estatus adulto. El vínculo paterno se plasma en un ciclo de intercambios recíprocos, diferidos y a largo plazo que se ven retribuidos posteriormente, lo que muestra que la relación paterno-filial se concibe a lo largo del ciclo vital en términos de interdependencia (Magazine y Ramírez 2007). Entre los nahuas de Guerrero, Good indica que el vínculo comienza con el nacimiento; al recibir el trabajo físico paterno en la infancia, el niño inicia su vida "endeudado", lo que lo compromete posteriormente a beneficiar a sus padres con el suyo. "En la relación de crianza, darle al niño el trabajo de uno constituye la base de la "paternidad' o la 'maternidad' [...] Los derechos sobre un niño se establecen al trabajar para él o ella; en estos casos el niño usa los términos nahuas correspondientes a 'mi madre' y 'mi padre' para las mujeres y los hombres que intervinieron en la crianza" (Good 2005: 288-289).

${ }^{9}$ Montoya Briones registra en Atla, una comunidad de tradición nahua de la Sierra Norte de Puebla, seis grupos de edad bien definidos: el cúnetl (desde el nacimiento a los 2 ó 3 años); el piltontli o telpócatl, y la piltontli o ichpócatl (de los 4-5 a los 12 ó 13 años), el telpochtontli y la ichpochtoltli (de los 13-14 a los 16-17 años), el telpochtli y la ichpochtli (de los 17-18 a los 22-23 años), el tlácatl y la sóatl (de los 24-25 a los 50-60), y el tectli y la tosi'tzi (de los 60 años en adelante) (Montoya Briones 1964: 103-104).
} 
Fuera de la familia inmediata el niño ayuda también a otros parientes y por ello recorre las casas recibiendo recados, encargos, tareas. Dirá: "Voy donde mi tío a cuidar sus borregos", "la tía quiere que le ayude en la cocina", "mi prima quiere que juegue con ella". Todos serán conscientes del tipo de trabajo que le pidan al niño según su edad, y lo retribuirán a su manera ${ }^{10}$. De este modo influirán en su educación moral y estarán encargados de incidir sobre su comportamiento para dirigirlo a convertirse en "persona".

En el ámbito comunitario también ayudan. Participan en las fiestas asistiendo a sus padres en la organización. Por ejemplo, ascienden con sus padres a los cerros a pintar de blanco las piedras con cruces el 3 de mayo, día de la Santa Cruz (Figura 2). Cuando los santos se "hospedan" temporalmente en las viviendas presiden las urnas en los traslados y tocan las campanillas por los caminos (Figura 3). En las mayordomías vigilan la recaudación del dinero o participan directamente en la elaboración de los arreglos. Un niño me explicó:

He visto cómo se ayudan todos los que vivimos aquí. Haciendo juntas en la delegación organizan a los mayordomos para adornar la iglesia con frutas y flores y hacer una portada en la entrada con flores y dulces.

\section{Otro niño agregó:}

Decomisan a varias personas o mayordomos que se encargan de la iglesia y pasan a cobrar de casa en casa para comprar las cosas necesarias; con los mayordomos se organiza también la gente para asear la iglesia ${ }^{11}$.

Las ayudas domésticas y comunitarias están estrechamente vinculadas con el desarrollo anímico de los niños. El espíritu y la socialización van

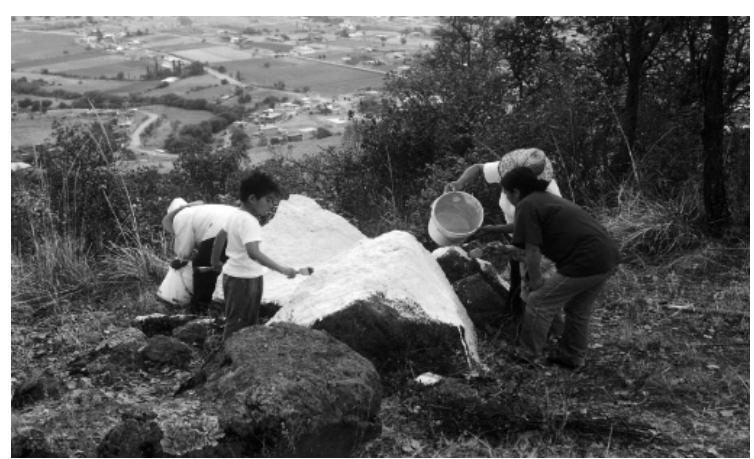

FIGURA 2.-Pintando las piedras que sirven de base a las cruces, 3 de mayo, día de la Santa Cruz, Santa María Tecuanulco. Fotografía del autor.

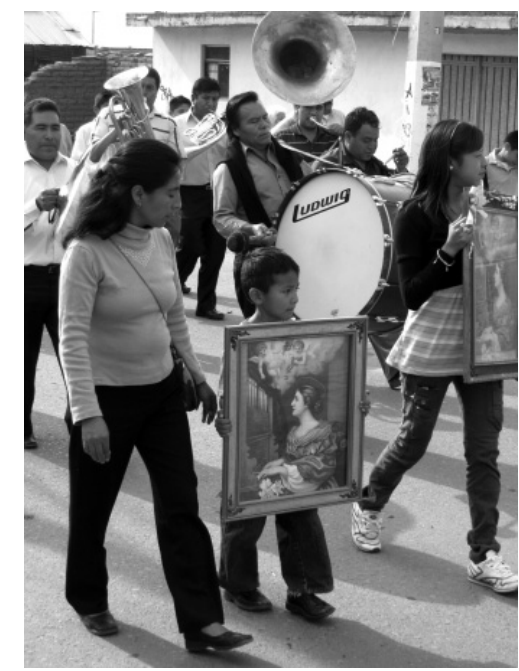

FIGURA 3.-Participación infantil en una procesión en honor a Santa Cecilia, patrona de los músicos, San Jerónimo Amanalco. Fotografía del autor.

\footnotetext{
${ }^{10}$ Véase Magazine y Ramírez (2007: 57-59).

${ }^{11}$ Testimonios recabados con cuestionarios realizados en la comunidad de Santa María Tecuanulco en junio de 2003.
} 
de la mano. El bebé nace dotado de un espiritu débil que se va fortaleciendo a medida que crece $^{12}$. Se preserva al niño del encuentro con los seres sobrenaturales y las enfermedades que, como el "susto", podrían afectarlo, enfermarlo y producir incluso su muerte. Pero lo importante aquí es destacar que el espíritu constituye el operador social del ser humano, es decir, aquel principio que le permite interactuar adecuadamente con los demás. Como el propósito es transformar al niño en una persona vinculada con sus parientes y dedicada a trabajar para ellos o ayudarlos, los padres recurren a ciertas manipulaciones rituales para afianzar el proceso. Además de involucrarlo en la cotidianidad de la Sierra, en realidad mucho antes, recogen una parte de su organismo que se supone se mantiene conectada con el espíritu de por vida: el "ombligo" (cordón umbilical). Lo reciben de manos de la partera junto con la placenta y entierran primero ésta en los terrenos de la casa; entonces, si se trata de un niño varón, llevan el "ombligo" hasta el monte y lo entierran con el propósito de que "salga muy bueno para cuidar borregos, sembrar y recoger leñan; si se trata de una mujer, lo entierran debajo de una de las esquinas del fogón o bajo del metate (el principal instrumento culinario) para que sea un ama de casa entregada a sus hijos y buena cocinera, en suma, una mujer hogareña. La vida del niño transcurrirá así ligada a su grupo doméstico desempeñando en compañía de otros las tareas propias de su sexo ${ }^{13}$.

${ }^{12}$ Los nahuas utilizan el término espíritu en castellano para designar una entidad separable, divisible y mortal asociada al alma (animancon) o principio vital general que habita en el corazón; el espíritu se disemina por el cuerpo humano y está compuesto por una serie de espíritus o entidades menores que residen en las coyunturas o zonas anatómicas donde late el pulso (Lorente 2011: cap. 3). Utilizo las cursivas al transcribir este término para señalar que, aunque se trata de un significante castellano, alberga en realidad una carga semántica nahua, un significado genuinamente indígena.

${ }^{13}$ Bernardino de Sahagún registró otro tanto entre los mexicas. En sus "De las abusiones que usaban estos naturales", en el apartado IX. "del ombligo", escribe: "Otra abusión tenían: cuando cortaban el ombligo a las criaturas recién nacidas: si era varón, daban el ombligo a los soldados para que le llevasen al lugar donde se daban las batallas; decían que por esto sería muy aficionado el niño a la guerra; y si era mujer, enterraban el ombligo cerca del hogar, y decían que por esto sería aficionada a estar en casa y hacer las cosas que eran menester para comer" (1999: 281). Prácticas similares han sido documentadas actualmente en otras regiones nahuas. Valgan tres ejemplos. En Cuetzalan, el cordón umbilical del varón se cuelga de las ramas de un árbol, que a partir de entonces se convierte en su protector; el de las niñas se coloca bajo el metate para que de adulta "sea fértil" y "alimente" bien a su familia (Aramoni Burguete 1990: 196-197). Escribe Olavarrieta sobre los Tuxtlas: "El ombligo del recién nacido se cauteriza con un calvo caliente, y junto con la placenta, debe enterrarse en una de las esquinas de la casa, donde persona alguna pise sobre ellos. Otros informantes piensan que el patio de la casa es el lugar donde debe llevarse a cabo el enterramiento. Este tratamiento especial para cordón umbilical y placenta tiene consecuencias importantes para la futura salud del recién nacido. Una vieja partera empírica, muy conocida en San Andrés Tuxtla, opinaba que la gente se debilitaría cada vez más, dado que en los hospitales arrojan a la basura los elementos citados. Los niños, entonces, resultan de 'espíritu débil', muy dados a enfermar. Otra informante manifestó que era indebido que en los hospitales 'tiren todo eso; porque es parte de uno, como el niño" (1977: 107, énfasis añadido). Según Montoya Briones, en Atla "el cordón umbilical y la placenta - itebuícal - se entierran en el solar [...]; el hoyo lo practica el padre del niño y la partera se encarga de enterrar el itehuical; encima se pone un poco de cal dibujando una cruz, lo que permitirá localizar el lugar sin dificultad el día del pakilistli, cuando los padrinos [de bautizo] del niño bailen con él a su alrededor". Los padrinos bailan "cargándolo, a fin de que 'crezca fuerte y sano'" (1964: 102, 99). Todos estos ejemplos muestran la importancia de la manipulación ritual del ombligo y la placenta en la construcción del niño como "persona". 


\section{EL "RESPETO", VALOR MORAL}

El respeto es el valor principal de la educación moral, pues permite dirigir el comportamiento del niño hacia la relación armónica con los demás. Antiguamente se utilizaba el término icatlasotla para designar este concepto, pero no se relaciona directamente con el sentido que posee en la tradición occidental; no se trata únicamente de ajustar el comportamiento a las clasificaciones jerárquicas basadas en el sexo o la edad. El "respeto" comprende un campo semántico más extenso. Para los nahuas implica establecer relaciones con otras personas susceptibles de ser retribuidas. Un individuo respetuoso actúa siempre de manera tal que su comportamiento genera lazos con los demás; crea vínculos estables, recíprocos, que se mantienen de forma continuada a lo largo del tiempo. Dicho sucintamente, icatlasotla implica la acción de dar, entregar, donar, que lleva consigo la reacción de devolver, denominada tlasocamachiliztli o "agradecimiento". Respetar consiste en dar y, una vez dado algo, implica por parte de la otra persona "devolver", que se traduce en retribuir y verbalmente en el acto de dar las gracias. Existen diferentes recursos que sirven como sustancia a esta relación: puede ser comida — una canasta llena alimentos-, ayuda, trabajo, servicios, e incluso las palabras en un saludo. La función fática del lenguaje es un excelente ejemplo cotidiano de lo que representa una interacción respetuosa: "¿Cómo está tu familia?" "Estamos bien, gracias a Dios". ¿Y tus hijos cómo están?" "Todos estamos bien".

Se trata de un mecanismo sutil que permite crear lazos a todos los niveles pues, emanando del individuo, involucra a su familia, a sus parientes lejanos, a la propia comunidad y finalmente a los difuntos y deidades. El respeto de una familia hacia otra crea una familia mayor. Porque el respeto persigue en última instancia unir, articular personas para formar entidades corporativas mayores que puedan cooperar en todos los ámbitos, sintiéndose unidas y protegidas por los lazos comunes ${ }^{14}$. El conflicto, el pleito, las actitudes agresivas son en este sentido todo lo opuesto al respeto: pelear y romper los lazos, no devolver la comida o abstenerse de retornar un favor suspende una relación, deshace los vínculos y aísla a las personas. Un sujeto asocial es considerado como un individuo enfermo; su actitud no le permitirá sobrevivir mucho tiempo en una sociedad que basa su concepto de vida en mantenerse unida. Una persona que "dice groserías, golpea, no come a sus horas ni con su gente" no es estrictamente una "persona".

En el seno de la familia el respeto se vuelve una actitud constitutiva. Como vimos en el apartado anterior, padres e hijos sostienen un vínculo de interdependencia. En este sentido son "respetuosos" los hijos que responden con corrección a sus padres ("devuelven" las palabras recibidas), aceptan el alimento preparado por éstos y "ayudan" en la vida doméstica cumpliendo las actividades prescritas que ya se indicaron.

\footnotetext{
${ }^{14}$ Escribe Lewis sobre Tepoztlán: "Los tepoztecos también buscan la seguridad mediante el respeto y la extensión de la relación de respeto, que estiman en mucho, pues la califican de segura. En tal relación, a cada parte se le garantiza una conducta respetuosa y llena de amistad, así como el cumplimiento de las obligaciones formales. La posición de respeto parece derivar de una posición social superior (económica o política), de la ancianidad, de la educación o de una relación formal y específica establecida entre dos individuos o familias, por ejemplo, parientes politicos o compadres" (1968: 182, énfasis añadido).
} 
En pocas palabras —escribe James Taggart (2003: 4) refiriéndose a los nahuas de la Sierra Norte de Puebla-, inculcar el respeto (icnoliz) es engendrar al niño para formarle como un ser humano (tacatiliya) para que tenga misericordia (teicneliliz) gracias a la cual el niño o la niña responden con consideración y son obedientes. Inculcar el icnoliz es un acto de amor (tazobtaliz).

Según este mismo autor, ser respetuoso tiene que ver con el verbo icnelia, que es "hacer bien a sí mismo, hacer bien a otro", y específicamente se relaciona con "el beneficio becho a otros" (Taggart 2003: 2) ${ }^{15}$. No en vano Molina traduce el verbo ixtilia como "respetar a otro" (2004: 47). El "respeto" tiene que ver con la cualidad relacional del individuo en su dimensión incluyente y constructiva ${ }^{16}$.

Pero este beneficio no implica ver únicamente al otro al que la persona se dirige, sino también las repercusiones que emanan de sus actos y cómo éstas pueden afectar a terceros, ya sea para bien o para mal. Ser respetuoso es cuidar las consecuencias de las obras a diferentes niveles, y esto hace que inculcar respeto en los niños sea tan decisivo para adecuarlos a la vida comunitaria ${ }^{17}$. El niño debe comprender que sólo es "persona" si pertenece —es decir, si contribuye y entrega el valor de sus relaciones- al grupo, y el grupo puede incluir tanto a la familia nuclear como a la extensa, a los muertos, al pueblo o al grupo de las comunidades que integran la región.

TRANSMITIENDO EL "RESPETO» POR MEDIO DE AMONESTACIONES Y DE RELATOS

Los nahuas emplean a menudo sentencias morales en sus conversaciones cotidianas, que pueden adoptar la forma de breves comentarios circunstanciales o de historias más elaboradas. En ambos casos no constituyen exhortaciones formalizadas dotadas de una estructura fija. Son contextuales y surgen flexibles en los instantes apropiados. Puede recurrirse a ellas en cualquier situación siempre y cuando la intención edificante y el público se correspondan.

Veamos un ejemplo. Amanda, una mujer casada de unos 40 años, se quejaba una y otra vez ante sus hijas del maltrato y humillación a los que le sometía su suegra, que vivía en su casa, a la que llamaba "la abuelita":

La abuelita — les confesaba a las niñas, que eran nueras potenciales- todo lo de por aquí de la casa lo lleva para sus hijas: los nopales, los agapandos, los epazotes... Lo lleva escondido en su ropa y lo va cambiando de lugar al salir para que no lo veamos... No es buena conmigo, nunca lo ha sido. Roba las cosas de la casa para llevárselas a sus hijas. Además pasa todo el día lavando sola la ropa y tendiéndola. Se enoja con el abuelito [su marido, el suegro de Amanda] porque no la ayuda. Nunca le ha ayudado; él va a sus

\footnotetext{
15 Taggart se basa en el diccionario de Frances Karttunen (1985: 220) para establecer esta correspondencia.

${ }_{16}$ "El respeto (manetzotl) —escribe Chamoux - es una calidad positiva de las personas, que un individuo tiene o no. Lo tiene si cumple escrupulosamente con sus obligaciones familiares, comunales y religiosas con cortesía y generosidad. Es un cualli tlacatl, o buena gente" (1987: 348).

17 Un caso semejante ha sido documentado entre los indígenas mazahuas, para quienes la educación infantil articula las nociones de "responsabilidad" y "reciprocidad" (véase Paradise y de Haan 2009).
} 
cosas. Por eso la abuelita no fue el otro día a la fiesta de casa de Martín [uno de los hijos del abuelito], porque él nunca la ayuda, no le tiene respeto ${ }^{18}$.

Este pequeño episodio posee una intención moralizante. Amanda recurre al mal ejemplo que le ofrece su suegra para mostrarles un comportamiento irrespetuoso a sus hijas. "La abuelita" roba las cosas de la casa, que pertenecen a la familia extensa en la que vive, para llevárselas a sus hijas, cuñadas de Amanda, perjudicando así directamente a sus nietas. Persiguiendo beneficiar a su descendencia inmediata perjudica las relaciones en el hogar. Es una mala suegra que actúa de forma indebida — "no es buena conmigo", se queja Amanda- y representa la antítesis de cómo alguien debe conducirse.

Pero el ejemplo no acaba ahí. "El abuelito", su marido, no la ayuda; por eso debe lavar y tender la ropa ella sola. Por eso la abuelita no asistió a la fiesta de uno de sus hijos, para poner en evidencia sus desavenencias con el abuelo. Ausentarse era una manera de devolver en negativo la falta de ayuda, no asistiendo a una fiesta -y probablemente no cocinando- cuando se asumía que debía hacerlo. La pareja de suegros esgrime un comportamiento egoísta, acaparador, insolidario — —van a sus cosas»—, que no sólo no produce consecuencias positivas sino que deriva en una suerte de cadena de retribuciones negativas que empeoran progresivamente la situación.

Con esta enseñanza las hijas aprenden cómo no deben conducirse en sus futuros papeles de nueras o suegras. Porque el respeto prescribe volcarse en su grupo doméstico y no aliarse con sus parientes consanguíneos a costa del bienestar del hogar. Las hijas reciben una lección sobre cómo actuar en su casa, cuando la tengan ${ }^{19}$. E indirectamente asumen que deben exigir la ayuda de su marido y cómo se pueden reprobar los comportamientos irrespetuosos: suspendiendo la ayuda dirigida a quien no las ayudó. En ciertas ocasiones esta intervención correctiva puede aportar (se deduce) buenos resultados.

En otra ocasión, María, una mujer ya madura, escuchó los comentarios de su hija de 17 años acerca de lo mucho que quería a su novio. El joven la frecuentaba a diario y la madre estaba preocupada. Cierto día, aprovechando la presencia de su otra hija menor, le espetó:

Hija mía, si te casas, que te pidan. No quiero que te salgas como el gato ${ }^{20}$.

Le pregunté entonces que por qué como el gato. Dijo que el gato es un animal doméstico que "se sale sin decir adiós y por ahí anda..." El gato es un "desagradecido". Noté que la chica entendía perfectamente a lo que su madre se refería, la hermana menor presente, también.

Para captar los matices debe atenderse al proceso del matrimonio. El noviazgo se da a edad temprana, entre los 13 y los 17 años, y la fiesta de quince años marca el momento en el que el matrimonio adopta una forma socialmente legítima. Pero cada vez son más frecuentes los casos en que el novio rapta o roba a la novia, algo abiertamente censurado y percibido con desagrado. "La mayor ilusión de mi mamá — dijo

\footnotetext{
${ }^{18}$ Relato grabado en la comunidad de Santa María Tecuanulco en junio de 2003.

${ }^{19}$ Véase al respecto el estudio de Mulhare (2003) sobre los comportamientos nahuas de género prescritos en relación con el concepto de "respeto".

${ }^{20}$ Conversación sostenida en junio de 2003 en la comunidad de Santa María Tecuanulco.
} 
María - era que todas las hijas nos casamos bien". Casarse bien implica efectuar el pedimento.

La ceremonia del "pedimento" es en sí respetuosa. Los padres del novio acuden acompañados por los fiscales y un chiquibuite (canasto) con pan, vino y dos cirios a casa de los padres de la muchacha para pedirla en matrimonio. Éstos comienzan poniendo pretextos para dotar de mayor valor a su hija, y terminan ofreciendo una comida a los padres del pretendiente. Con el rito dos familias extrañas entablan un vínculo que las convertirá en un gran grupo unificado de parientes en el futuro.

Pero el robo transgrede las normas. Es un arrebato individual que busca únicamente la unión de la pareja, un acto egoísta que frustra los lazos sociales. No une a las familias. Obviar el pedimento y huir "como el gato" es comportarse como un animal que "sale" de la casa "sin decir adiós y por ahí anda"; es "desagradecido". El gato no es respetuoso. Y el hecho aclara un aspecto central que distingue radicalmente a los animales de las "personas". En una situación semejante escuché decir de un perro que iba a una fiesta y consumía la comida sin entregar nada a cambio. "El perro come y se marcha". El perro actúa como un gorrón que se beneficia de los alimentos sin entregar su esfuerzo en prepararlos. Los nahuas recurren a los animales como un ejemplo de conducta social inapropiada. Nos dice Taggart:

La calidad de icnoliz [respeto] está presente en los seres humanos cuando los padres se molestan en inculcárselo a sus hijos y no existe en los animales, incluyendo a los que han sido domesticados [...] ("Una bestia piensa como una bestia, no tiene respeto") [...] [Pero sí] se muestra hacia los animales cuando, por ejemplo, un hombre ayuda a un animal herido (Taggart 2003: 4).

La distinción radical entre animales y humanos radica entonces en el carácter relacional de los segundos, en su capacidad —o incapacidad- de actuar de manera recíproca y no guiados por el egoísmo que caracteriza a los primeros. Inculcar "respeto" a los niños implica por tanto dotarlos de humanidad (Ibid.).

Aprender a encauzar el deseo individual de contar con una pareja y convertirlo en un recurso mediante el cual se generan vínculos interfamiliares es un buen ejemplo de lo que significa "casarse bien" y con "respeto".

Veamos un último ejemplo. En cierta ocasión, durante una reunión familiar, un hombre narró a los presentes, entre los que se encontraban algunos niños, un episodio de enfermedad relacionado con los espíritus del agua o abuaques. Su hijo había ido a jugar al manantial a una hora indebida y había sido capturado por estos seres. Al quedar privado de espíritu su conducta se había transformado completamente. Contó su padre:

Después de que lo agarraron rompió unos cuadros de espejos que tenemos dentro de casa y las estampas de unos santos. "Nos perdió el respeto —exclamó—: nos hablaba mal, nos golpeaba todo el tiempo y rompía cosas!n Un día se subió al tejado de la casa y chiflaba mirando hacia el cielo [...], por las noches salía solo a caminar y se perdía, tampoco comía a sus horas... ${ }^{21}$.

El episodio revela una serie de hechos que resumen lo que constituye conducirse $\sin$ "respeto". Las actitudes irrespetuosas presiden toda la vida del enfermo: "nos

${ }^{21}$ Relato consignado en mi diario de campo, comunidad de San Jerónimo Amanalco, 5 de abril de 2004 . 
hablaba mal, nos golpeaba todo el tiempo y rompía cosas [...] se subía al tejado de la casa y chiflaba [...] no comía a sus horas". Vayamos por partes. Ya vimos que el espíritu humano alberga el operador social del individuo. Un sujeto desprovisto de espíritu es considerado entonces un asocial, un "no-humano" que rompe los lazos recíprocos con todos los que le rodean. No es extraño que los nahuas utilicen el término "loco" para designar a estas personas: no es el trastorno mental sino la suspensión de su dimensión relacional lo que hace de un individuo un perturbado. Los niños allí presentes escuchaban atentos. El enfermo se había deshumanizado, adoptando un comportamiento "ensalvajado" y convirtiéndose en algo aún peor que en un animal. El enfermo se había transformado en un ser radicalmente destructivo en términos sociales. Pegaba a sus padres, producía destrozos, chiflaba, huía de casa, no comía a sus horas. Este último aspecto puede resultar un tanto extraño. No obstante, diciendo que no se alimentaba en el momento apropiado el padre mostraba en negativo un comportamiento familiar constitutivo: comer a las horas prescritas implica "comer con otros"; la comida se considera un momento de consolidación de vínculos intragrupales. Comer cada quien por su lado es reprobado. Compartir una comida produce unificación familiar, "representa la dependencia mutua" y actúa como una metáfora poderosa para definir a un grupo consolidado (Good 2001: 278-279).

Los niños que escuchaban el episodio aprendían sobre los peligros de exponerse a las agresiones de una deidad. Las represalias de los espíritus del agua tornan al humano en un ser irrespetuoso. Hay que cuidarse de acudir despreocupadamente al manantial y seguir los consejos de los mayores que indican no hacerlo a las doce del mediodía, cuando son más virulentos ${ }^{22}$. Pero a través del relato los niños aprendían al mismo tiempo una serie de preceptos morales: a los padres no se les debe nunca gritar, contestar de malas maneras y mucho menos agredirlos, un niño respetuoso no se escapa por la noche de su casa ni consume sus alimentos por separado. Éstos son indicios de que su constitución anímica está mal y de que, privado de espíritu, puede acabar transformado en un ser amoral "ensalvajado" alejado del resto de los humanos.

\section{INCULCANDO EL “RESPETO" A TRAVÉS DE LOS HECHOS}

Hemos visto que los relatos de episodios morales surgen en situaciones específicas de la vida diaria, y esto se debe a que los niños participan en ella sin restricciones. Pero la atención a los consejos orales no se encuentra disociada sino que antes bien se articula con las actividades formando una unidad complementaria. Escuchar y participar se encuentran imbricados en el mismo proceso educativo ${ }^{23}$.

\footnotetext{
${ }^{22}$ He analizado detalladamente en otro lugar (Lorente 2006, 2011: cap. 5) cómo mediante este tipo de relatos los niños aprenden aspectos más generales de la cosmovisión y la interiorizan como un operador cognitivo.

${ }^{23}$ Escriben Rogoff et al. en su estudio clásico: "La observación aguda y el 'estar a la escucha' son especialmente valorados y empleados en algunas comunidades culturales en las cuales los niños forman parte de las actividades comunitarias que realizan los adultos" (2010: 95). Y añaden después más extensamente: «Los niños en todas partes aprenden por observación y por la escucha
} 


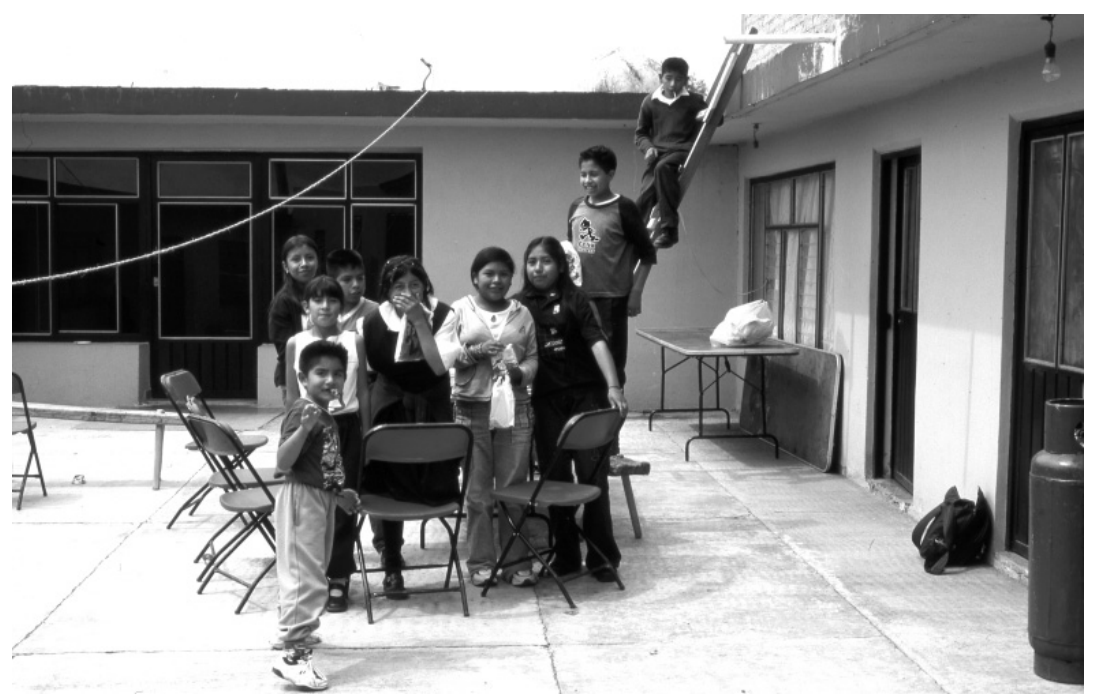

Figura 4.- Niños de Santa María Tecuanulco durante una fiesta de cumpleaños. Fotografía del autor

Algunos ejemplos sirven para ilustrarlo. Volvamos un momento a la comida. Un alimento aislado es ante todo un instrumento para formar relaciones. Algo tan simple como un caramelo es un recurso excepcional. Cuando un niño recibe de sus padres una paleta (piruleta) o una bolsa de dulces no debe acapararla para sí, no debe retirarse a un lugar apartado para consumirla en secreto ni ocultarla en el bolsillo. El verdadero valor del caramelo es otro: al dárselo, el padre o la madre mira en derredor y descubre la presencia de otros niños. La situación tiene lugar en un mercado, en los asientos del transporte público, en una reunión familiar. El niño coge el caramelo y el padre señala con el dedo a otro niño: "Compártele". El niño extiende el caramelo o coge uno de los dulces y se lo da al otro, algunos infantes pueden incluso introducírselo en la boca. El otro niño disfruta durante un rato la paleta y se la devuelve. La interacción se prolonga varios minutos. Un observador externo podría encontrar muy extraño este comportamiento. Por un lado esperaría una reacción de desagrado ante la obligación de compartir el caramelo. Por otro imaginaría la censura de los padres ante este proceder tan poco higiénico. Pero no ocurre así. Los dos niños se alternan, se miran, se ríen, los padres no consideran el acto como algo "Sucio". Cuando existen varios caramelos el otro niño recibe unos cuantos. Cada cual se

activa en las actividades de los adultos y de otros niños. El aprendizaje mediante la observación aguda y la escucha, anticipando la contribución, parece ser especialmente valorado y resaltado en comunidades donde los niños tienen acceso al aprendizaje por medio del involucramiento informal en la comunidad. Ellos observan y escuchan atentamente y con iniciativa, y se espera su colaboración en las actividades compartidas cuando se sientan listos. Esta tradición, a la que llamamos 'participación intensa en comunidades', destaca en muchas comunidades americanas indígenas [...] La participación intensa en comunidades es una forma muy valiosa de fomentar el aprendizaje" (2010: 96, véase la versión inglesa del artículo: Rogoff et al. 2003). 
va satisfecho. En este sentido un taco de tortilla, un tamal o una fruta, es decir, las raciones de comida individuales, responden al mismo propósito.

Y lo mismo ocurre con los juguetes: "déjale jugar a tu primo, déjale». El juguete es idóneo para formar agrupaciones de niños que reparten su atención entre ellos (Figura 4). Los juguetes deben compartirse y así cumplen su función. Los niños juegan juntos y aprenden a mantener relaciones respetuosas basadas en la colaboración recíproca, no suelen pelearse por ellos ni arrebatarlos. El juego es concebido como un recurso estrictamente infantil en su dimensión colectiva:

Los grandes no juegan — dijo un niño de cinco años al que le había regalado un trompo (una peonza)—: esto es para jugar los niños ${ }^{24}$.

Una situación muy emotiva surgió cuando la hija de una señora observó por la ventana a los niños que salían del colegio. Corrió a buscar sus juguetes y los acercó hasta el cristal para llamar la atención de los niños. Los agitaba con sus manitas. Quería que acudieran a jugar con ella para no tener que hacerlo sola. Los juguetes se habían convertido en un recurso relacional.

Otro ejemplo. A los ocho o nueve años los niños se enfrentan a una decisión importante. Deben hacer la comunión. Y esta situación les brinda a los padres un buen momento para inculcarles "respeto". No tiene que ver con el carácter católico de la celebración. Un episodio que registré me causó cierto desconcierto. La familia extensa comía mientras la niña involucrada garrapateaba cosas en un cuaderno, sentada en un rincón. En cierto momento se levantó y le enseñó la hoja a su madre. Volvió a su rincón. Diez minutos después repitió la operación con su padre. Para entonces yo ya estaba persuadido de que ocurría algo importante. La niña no estaba, como yo creía, haciendo un dibujo. Los parientes no la miraban pero estaban pendientes de su cuaderno.

La niña terminó su tarea y volvió con su padre. Entonces el contenido del cuaderno salió a la luz. Era una lista de los parientes que ella había invitado a su comunión. Yo no entendí por qué el padre no había tomado el cuaderno desde un principio y hecho en breve la lista consultando a su hija. No se habría invertido tanto tiempo. El problema se habría resuelto mucho antes. Pero entonces reparé en que lo principal no era el contenido de la lista; el proceder respondía a una pedagogía: la niña estaba aprendiendo a "elegir" parientes.

Entonces la discusión se tornó pública y familiar: "לhas incluido al tío Miguel?", preguntó la abuela; “ino te habrás olvidado del hermano mayor de papá?», dijo la madre; "te has saltado a Juan, el cuñado de tu hermano", añadió el padre. Este tipo de comentarios se prolongó durante un buen rato. La niña respondía, objetaba invitar a éste o a aquél o modificaba su lista con nuevos nombres. Nunca se censuró el número de parientes, en el sentido de que pudiera incrementar los gastos; el económico no era el criterio.

La intervención conjunta de la familia orientaba a la niña por la vasta genealogía. El propósito estaba claro: había que invitar a quienes invitaron a los padres en algún momento y hacer nuevas invitaciones pero conscientes de que implicaban una con-

${ }^{24}$ El comentario procede de un diálogo registrado en la comunidad de Santa María Tecuanulco en junio de 2004 . 
tra-invitación. Elegir parientes no era algo sencillo, tenía repercusiones a medio y largo plazo $^{25}$. Servía para extender las redes sociales de la familia a través del niño - tenía pues un carácter supraindividual- pero en esta ocasión constituía un hecho más importante: era el primer momento en la vida del niño en que éste "elegía" a sus parientes, es decir, en el que realizaba una selección deliberada que le hacía tomar consciencia de que su existencia, a partir de entonces, incluía a bastante más gente que su familia inmediata. Al hacerlo distinguía con qué parientes debía contar en el futuro y por qué motivo, y experimentaba por primera vez el hecho de crear y contraer obligaciones a través de una fiesta. Con este paso el niño avanzaba aún más hacia el concepto de "persona", aprendía el "respeto" que implica llenar su vida de vínculos en una suerte de parentela libremente elegida, una configuración individual de relaciones que, a partir de sucesivas ceremonias, iría creciendo cada vez más y extendiéndose. La lista de invitados no podía entonces ser hecha por los padres o abandonada al descuido. Constituía su red social. Al respecto nos dice Catharine Good:

Todas las personas que forman parte de la sociedad nahua participan en dos redes de vínculos: hacia las personas con quienes "trabajan juntos como uno", es decir, el grupo doméstico [...], y hacia "su gente", las personas que conforman su red de relaciones fuera del grupo doméstico inmediato. Es importante destacar que dentro de una unidad doméstica determinada los diferentes miembros pertenecen a diferentes redes recíprocas; comparten algunas relaciones pero la red de "su gente" de dos personas distintas nunca es la misma. En la práctica estos vínculos crean sistemas de relaciones y apoyos complementarios o, a veces, tensiones ya que todo el mundo está sujeto a diferentes presiones y lealtades en distintas situaciones. [...] La existencia de estas dos redes explica una aparente contradicción: los nahuas operan dentro de un marco de referencia colectiva que abarca al grupo doméstico, sus redes sociales más amplias, su comunidad como entidad y, a veces, el grupo étnico regional; a la vez, mantienen personalidades muy fuertes como individuos y pueden actuar con mucha independencia frente a cualquiera de estos grupos de "su gente" mientras se apoyan en otros (Good 2005: 286-287).

Hacer la lista de invitados es un acto central en la educación moral y aprender a elegir parientes una enseñanza que tiene más importancia y utilidad para el niño que la propia comunión en su sentido sacramental.

Veamos un último ejemplo. En las situaciones anteriores hemos atendido a cómo los niños pequeños utilizaban los juguetes y caramelos como recursos para activar el respeto y cómo, a la edad de ocho años, la lista de invitados servía para tomar conciencia de lo que representa convertirse en "persona" creando redes recíprocas respetuosas. Ahora analizaremos un aspecto complementario de esta formación: el vínculo que el niño aprende a sostener con los muertos, sus antepasados que residen en el otro mundo, a través de las comidas que se les brindan como un acto "respetuoso".

Durante la festividad del Día de Muertos todos los parientes patrilineales se reúnen en la casa del abuelo. Allí elaboran el "pan de muertos" que será ofrendado en los distintos altares domésticos de las diversas familias. Éstos contienen una serie de

${ }^{25}$ Las listas de parientes y los flujos de bienes y aportaciones de ayuda también pueden observarse en las fiestas de quince años celebradas en las comunidades de tradición nahua de la Tlaxcala rural, donde "los quince años de las jóvenes suelen celebrarse con una fiesta que reúne a numerosos parientes, personas relacionadas por vínculos de compadrazgo y otros invitados. En algunas celebraciones [...] los invitados pueden alcanzar el número de quinientos" (Carrasco Rivas y Robichaux 2005: 462). 
alimentos entre los que destacan las figuras de pan cuyo aroma será consumido por los difuntos.

De los tres años de edad en adelante los niños participan activamente en su elaboración. Se reúnen con sus madres y colaboran ejercitándose en el modelado de las figuras - palomas, conejos, pollitos, medias lunas, muñecos con brazos y piernas-, viviendo desde dentro todo el proceso. Los niños hacen figuras aplastando la masa con pequeños rodillos, mientras las mujeres dan formas a las figuras y hablan entre ellas; una explica a las otras cómo vio en sueños la llegada de sus difuntos exigiendo comida. Los niños confeccionan figuras parecidas a las de los padres, más imperfectas y pequeñas, que son colocadas junto a las demás y cocidas también en el horno. Amasan un pan idéntico y en miniatura, que será después ofrendado en los altares con igual seriedad que el elaborado por los adultos.

Toda una mañana amasan y forman figuras escuchando los comentarios de las mujeres sobre los muertos y la importancia que reviste tenerlos satisfechos. Precisan de los vivos para mantenerse y, por medio de la comida, podrán subsistir y retribuir sus dones a los humanos: suerte en el trabajo, mayores ingresos, protección, salud y éxito en la siembra. Los niños hacen las figuras con esmero; no se trata de ningún juego, de su calidad dependerán los contradones de los difuntos que redundarán en su propio bienestar y el de la familia ${ }^{26}$.

Mientras los hombres se ocupan de preparar primero la masa e introducir después las figuras en el horno, los niños trabajan en compañía de las mujeres, que son las expertas en el manejo de la comida en el hogar. Alimentar es siempre un acto "respetuoso", pero en esta ocasión cobra un significado especial. Alimentar a los difuntos es prolongar el sistema de intercambios recíprocos con seres humanos que no son ya totalmente humanos, pues carecen de cuerpo y habitan otra dimensión. Al hacer el pan la red del respeto trasciende los nexos comunes para englobar la comunidad extrahumana de difuntos con los que también se puede - y se debe- mantener una relación duradera atendiendo a las normas prescritas. Una persona moral cuida tanto a sus parientes vivos como a sus muertos, y haciendo sus primeras figuras el niño aprende que no será nunca un adulto completo si no se ocupa de sus muertos, si no les "ayuda" compartiendo con ellos sus bienes y el alimento a través de su esfuerzo ${ }^{27}$.

\section{EL PROBLEMA DE LA ESCOLARIZACIÓN CONTRADICTORIA: APRENDIENDO EL «RES- PETO" MESTIZO}

Las actividades domésticas corren paralelas a la educación en la escuela. En la Sierra la escolarización constituye un valor social, que se manifiesta en el deseo de la mayoría de los padres por que sus hijos estudien e ingresen en la universidad o en los conservatorios de música. Ser músico está bien remunerado y posee un considerable estatus social. Pero la educación escolar confiere por sí prestigio pues separa al niño de la imagen del "indio", tan estigmatizadora para los serranos que abandonaron el uso del náhuatl hacia 1970 y avanzan ahora decididos, al menos exteriormente, a

${ }^{26}$ Estas observaciones sobre el Día de Muertos corresponden a las notas consignadas en mi diario y proceden de la comunidad de Santa Catarina del Monte, 27 de octubre de 2004. 
convertirse en "mexicanos" modernos. Su actitud revela en gran parte el deseo de no ser censurados socialmente dentro y fuera de sus comunidades con términos despectivos.

Los niños asisten al colegio desde las ocho de la mañana hasta la una de la tarde. Las clases reúnen a unos veinte alumnos, separados en primaria y secundaria, que son instruidos por dos o tres maestros del pueblo o foráneos. El conjunto de las asignaturas responde sucintamente, en su didáctica y contenido, a los parámetros de instrucción formal establecidos por el Estado y dirigidos a formarlos como buenos ciudadanos adoptando una cultura de carácter "mestizo". Según el proceso de cambio forzado de identidad que caracterizó a la política educativa mexicana desde el siglo $\mathrm{XX}^{28}$, los maestros tienen muy claro que pretenden hacerlos "evolucionar", alejándolos en lo posible de su condición subalterna, es decir, del mundo indígena campesino de tradición nahua.

Los niños deben expresarse en español y vestir uniforme, y entre los valores que reciben en las escuelas destaca un concepto de "respeto" muy diferente del que gobierna su existencia cotidiana. El respeto cobra en la escuela otro sentido: se impregna del contenido mestizo de tradición española ${ }^{29}$. El maestro lo enseña a través de la disposición de las aulas y las intervenciones por turnos que deben mantener un orden basado en la jerarquía. Se impone un esquema de preguntas y respuestas, de observancia de las categorías de grado y edad, de maneras de conducirse y desplazarse que poco tienen que ver con las nociones sociales nahuas. Esta formación afecta todas las facetas del contexto escolar, desde la dinámica de enseñanza hasta el comportamiento en los recreos (Figura 5). Sin embargo, destacaremos dos situaciones que resultan especialmente ilustrativas.

Cada lunes, a las ocho en punto de la mañana, antes de entrar en el aula, los alumnos se distribuyen formando filas frente al edificio. Éstas separan a los alumnos de primaria de los de secundaria y, en una segunda división, a los niños de las niñas. Tiene lugar entonces la ceremonia de "rendir los honores a la bandera". El maestro ha seleccionado para la ocasión, dentro del grupo al que le toque, al niño más des-

${ }^{27}$ Pueden consultarse al respecto los estudios de Good sobre el culto a los muertos entre los nahuas de Guerrero y el significado de compartir con ellos la "comida" como una forma de entregarles los humanos su "trabajo" (Good 2001 y 2004).

${ }^{28}$ Escribe Robichaux acerca del "proceso de cambio forzado de identidad": "Parecería que la idea de Manuel Gamio de que el español debía ser la vía de acceso a la civilización occidental en México se impuso de tal modo que, en el sistema escolar de la última mitad del siglo XX y en la mentalidad de los profesores, ya no había lugar para el náhuatl, ni siquiera para el recreo y mucho menos en el salón para dar explicaciones en esa lengua a aquellos chicos que tenían dificultades de comprensión de la materia. Si agregamos la presencia de la televisión que, desde fines de los setenta, se generalizó [...], podemos considerar como lógicas la aceptación y la profundización en la comunidad de un sistema de valores identificado con la modernidad en el cual se confirmaba cada vez más la superioridad de la cultura mestiza nacional y la ventaja de suprimir 'lo indio'. En el contexto de la creciente desvalorización de las actividades rurales con la imperante política nacional de la industrialización - en paralelo con el contexto local de una rápida proliferación del trabajo asalariado_-, la nueva pauta quedó muy clara para todos" (Robichaux 2005b: 80, véase también la p. 95).

29 Véase un contraste entre los valores morales nahuas y mestizos en los relatos analizados por Taggart (1983 y 1997). 


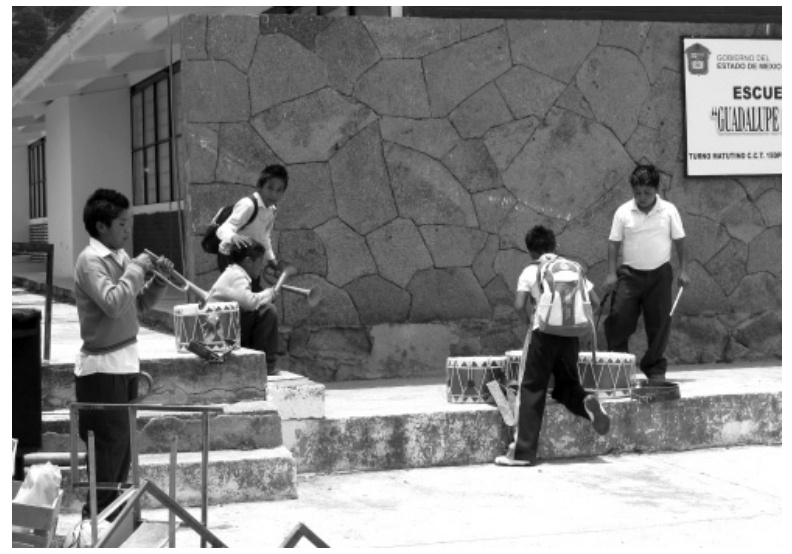

Figura 5.-Ensayando en el patio del recreo para la fiesta de fin de curso, Santa María Tecuanulco. Fotografía del autor. tacado por su comportamiento y calificaciones para que sea el abanderado. Este reconocimiento es un privilegio que se ostenta con orgullo. Enarbolando la bandera mexicana, el niño recorre el patio. Suenan las marchas militares interpretadas por otros alumnos mientras todos los asistentes saludan marcialmente con la mano cruzada sobre el pecho.

No es difícil descubrir en esta representación estereotipada de carácter militar los signos del respeto mestizo. Reina la jerarquía en todos los nive-

les. Las filas atienden a las divisiones por grado escolar y sexo, cada semana preside el acto una clase, en ella un niño es ensalzado por su comportamiento adecuado y sus méritos para que porte la bandera y recorra el recreo. Las marchas militares ritman el paso. La bandera, el emblema de la identidad nacional, es reverenciada como símbolo máximo de respeto. El acto tiene evidentes repercusiones para los niños: una noción muy estereotipada y precisa de conducta es aplicable a todas las situaciones en el seno de las escuelas. El respeto mestizo rige el colegio.

Otro ejemplo. Todo el año los niños han estado sometidos a diversas manifestaciones del mismo principio. En junio llega fin de curso. La ceremonia de clausura es un acto importante. Los alumnos ensayan coreografías para representar un "bailable" ante sus padres. Una de estas escenificaciones ofreció material muy interesante.

Los niños lucían camisa y calzón blancos y las niñas trenzas y faldas, calzando todos huaraches (sandalias). Se habían convertido en "inditos". Habían asumido en un disfraz los rasgos identitarios que el pensamiento mestizo confiere unilateralmente a los indígenas, proyectaban la mirada del "otro" sobre sí mismos. El maestro aparecía muy orgulloso y los padres encantados. "Mira a mi hija, qué linda — dijo una madre-: me costó bastante hacerle las trenzas". Observé sorprendido. No lograba entender lo que ocurría. ¿Los nahuas serranos disfrazados de nahuas? ¿Vestidos de indígenas como si fueran mestizos? Sin

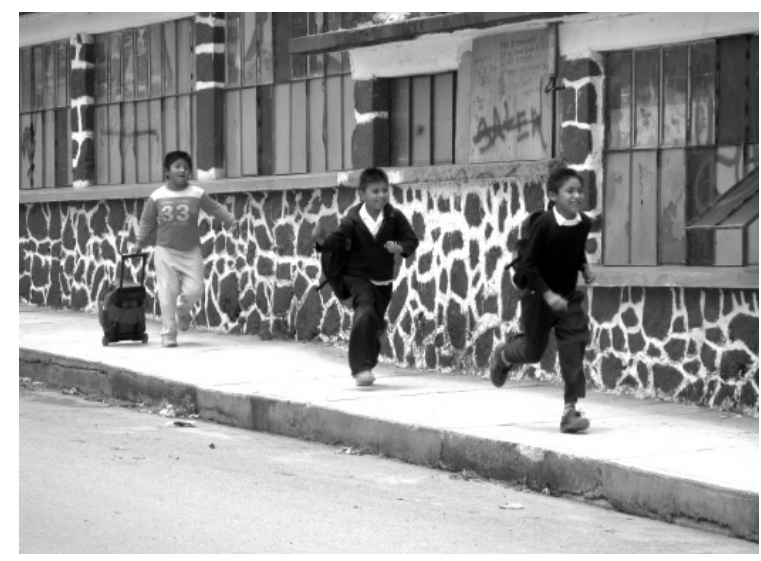

FiguRA 6.-Saliendo del colegio, San Jerónimo Amanalco. Fotografía del autor. 
duda era un acto moderno: sólo un no-indígena podía adoptar ese disfraz caricaturesco para jugar a ser, durante un rato, "indio". Actuando así representaban a los indígenas de otras áreas, ellos ya no lo eran; no había forma más clara de conjurar su indianidad relegada.

¿Podía el año escolar tener mejor cierre? La transformación perseguida por el maestro hallaba su eco en la aceptación de los padres, que asistían satisfechos. La escuela estaba cumpliendo su tarea (Figura 6).

\section{CONCLUSIONES}

Atendiendo a lo dicho, podría llegar a pensarse que existe una contradicción insalvable entre la educación indígena familiar del "respeto" y la formación escolar desindianizadora. Pero no es del todo cierto. Los nahuas las manejan más o menos conscientemente con distintos propósitos. El "respeto" mestizo resulta útil para enfrentar contextos urbanos o para evitar la discriminación por su origen. Fuera y dentro de un pueblo se oye a menudo a los habitantes decir de sus vecinos: "aquí estamos un poco más civilizados, allá se ven las mujeres con sus trenzas, son más como indígenas", "sus viejitos hablan el náhuatl", "porque nuestra tradición es un poco menos que la de ellos, nuestra fiesta patronal es más ordenada ${ }^{30}$. Los niños entienden y pueden moverse en esta lógica.

Pero más allá de estas manifestaciones la educación escolar formal tiene pocas repercusiones en su vida cotidiana. El respeto mestizo no hace "personas". Una vez en el exterior de la escuela el niño "pertenece" a distintos parientes que ejercen sobre él una presión moralizadora. Recurriendo a todos los medios que se encuentren a su alcance tratan de convertirlo en un individuo relacional que no percibe ninguna separación entre existencia y aprendizaje, pues a lo largo del día

el tiempo y el espacio del aprendizaje no están predefinidos: cualquier momento y cualquier lugar son propicios de antemano, y son las circunstancias concretas los que los transforman momentáneamente en tiempos y espacios para la transmisión [...] la duración de lo que podríamos denominar los actos elementales de enseñanza [...] puede abarcar desde algunos segundos hasta varias horas consecutivas (Chamoux 1992: 75).

El "respeto" indígena no puede cuestionarse porque es algo "natural", "dado", constitutivo de la persona y no fácilmente objetivable. La educación con los hechos y los relatos constituye la vida del niño, es en sí su infancia. Convertirse en un individuo "ensalvajado" conlleva muchos riesgos para él y para su entorno, por lo que más le vale ser respetuoso. Aprender el "respeto" en los vínculos suegra-nuera, el contexto del matrimonio, la relación con los animales y espíritus del agua, utilizando juguetes y dulces, haciendo una lista de invitados o amasando pan de Día de Muertos es sólo una faceta de una transmisión que le enseña que los nexos sociales son extensivos, englobantes, totalizadores, abarcando desde la familia nuclear o extensa hasta la comunidad y los difuntos.

\footnotetext{
${ }^{30}$ Testimonios recabados en la comunidad de Santa María Tecuanulco en junio de 2004.
} 


\section{BIBLIOGRAFÍA CITADA}

Aramoni Burguete, M. E. 1990. Talokan tata, talokan nana: nuestras raíces. Hierofanias y testimonios de un mundo indigena. México: Conaculta.

Bolin, I. 2006. Growing up in a Culture of Respect. Austin: University of Texas Press.

Carrasco Rivas, G. y Robichaux, D. 2005. "Parentesco, compadrazgo y ayuda: el caso de las fiestas de quinceañeras en Tlaxcala", en D. Robichaux (comp.), Familia y parentesco en México y Mesoamérica. Unas miradas antropológicas: 461-493. México: Universidad Iberoamericana.

Chamoux, M. N. 1987. Nabuas de Huauchinango. Transformaciones sociales en una comunidad campesina. México: INI, CEMCA.

Chamoux, M. N. 1992. Trabajo, técnicas y aprendizaje en el México indigena. México: CIESAS, CEMCA.

De León Pasquel, L. 2005. La llegada del alma. Lenguaje, infancia y socialización entre los mayas de Zinacantán. México: CIESAS, Conaculta, INAH.

De León Pasquel, L. (coord.). 2010. Socialización, lenguajes y culturas infantiles: estudios interdisciplinarios. México: CIESAS.

Dehouve, D. 2008. "El venado, el maíz y el sacrificado", Diario de campo, Cuadernos de Etnología 4. México: INAH.

Good Eshelman, C. 2001. "El ritual y la reproducción de la cultura: ceremonias agrícolas, los muertos y la expresión estética entre los nahuas de Guerrero", en J. Broda y Báez-Jorge, F. (coords.), Cosmovisión, ritual e identidad de los pueblos indigenas de México: 239-297. México: Conaculta, FCE.

Good Eshelman, C. 2004. "Trabajando juntos: los vivos, los muertos, la tierra y el maíz", en J. Broda y Good Eshelman, C. (coords.), Historia y vida ceremonial en las comunidades mesoamericanas: los ritos agrícolas: 153-176. México: INAH, UNAM.

Good Eshelman, C. 2005 “Trabajando juntos como uno’: Conceptos nahuas del grupo doméstico y la persona", en Robichaux, D. (comp.), Familia y parentesco en México y Mesoamérica. Unas miradas antropológicas: 275-294. México: Universidad Iberoamericana.

Karttunen, F. 1985. An Analytical Dictionary of Nabuatl. Austin: University of Texas Press.

Lastra de Suárez, Y. 1980. El nábuatl de Texcoco en la actualidad. México: UNAM.

Lewis, O. 1968. Tepoztlán. Un pueblo de México. México: Mortiz.

Lorente Fernández, D. 2006. "Infancia nahua y transmisión de la cosmovisión: los ahuaques o espíritus pluviales en la Sierra de Texcoco (México). Boletín de Antropología Universidad de Antioquia 20, n. 37: 152-168.

Lorente Fernández, D. 2010. "Trayectoria metodológica de una investigación etnográfica en México". Revista Española de Antropología Americana 40 (1): 85-110.

Lorente Fernández, D. 2011. La razzia cósmica: una concepción nabua sobre el clima. Deidades del agua y graniceros en la Sierra de Texcoco. México: CIESAS, Universidad Iberoamericana.

Magazine, R. y Ramírez, M. A. 2007. "Continuity and Change in San Pedro Tlalcuapan, Mexico: Childhood, Social Reproduction, and Transnational Migration", en Cole, J. y Durham, D. (eds.), Generations and Globalization: Family, Youth and Age in the New World Economy: 52-73. Bloomington: Indiana University Press.

Molina, fray A. de. 2004 [1970]. Vocabulario en lengua castellana y mexicana y mexicana y castellana. México: Porrúa.

Montoya Briones, J. de J. 1964. Atla: Etnografía de un pueblo nábuatl. México: INAH.

Morayta, M.; Good, C.; Melgar, R.; Paulo Maya, A. y Saldaña, C. 2003. "Presencias nahuas en Morelos", en La comunidad sin limites. La estructura social y comunitaria de los pueblos indigenas de México. Vol. II: 17-102. México: INAH.

Mulhare, E. 2003. "Respetar y confiar: ideología de género versus comportamiento en una sociedad post nahua", en Robichaux, D. (comp.), El matrimonio en Mesoamérica ayer y hoy. Unas miradas antropológicas: 267-290. México: Universidad Iberoamericana.

Nutini, H. e Isaac, B. L. 1974. Los pueblos de habla nábuatl de la región de Tlaxcala y Puebla. México: INI. 
Olavarrieta, M. 1977. Magia en los Tuxtlas, Veracruz. México: INI, Conaculta.

Paradise, R. y De Haan, M. 2009. "Responsibility and Reciprocity: Social Organization of Mazahua Learning Practices." Anthropology and Education Quarterly 40 (2): 187-204.

Robichaux, D. 2001. "Cultura, economía y grupo doméstico en México: una crítica y una propuesta desde la antropología", en Ribeiro, M., Gondeau, G. y Hernández, S. (coords.), La familia en América del Norte: evolución, problemática y política: 265-319. México: Ed. Trillas.

Robichaux, D. 2005a. "Principios patrilineales en un sistema bilateral de parentesco: residencia, herencia y el sistema familiar mesoamericano", en Robichaux, D. (coord.), Familia y parentesco en México y Mesoamérica: unas miradas antropológicas: 167-275. México: Universidad Iberoamericana.

Robichaux, D. 2005b. "Identidades cambiantes: 'Indios' y 'mestizos' en el suroeste de Tlaxcala". Relaciones. Estudios de Historia y Sociedad 26 (104): 57-102.

Rogoff, B. et al. 2003. "Firsthand Learning through Intent Participation". Annual Review of Psychology 54 (1): 175-203.

Rogoff, B. et al. 2010. "El aprendizaje por medio de la participación intensa en comunidades", en León Pasquel, L. de (coord.), Socialización, lenguajes y culturas infantiles: estudios interdisciplinarios: 95-134. México: CIESAS.

Sahagún, fray B. de. 1999 [1954]. Historia general de las cosas de Nueva España. México: Porrúa.

Taggart, J. M. 1975. Estructura de los grupos domésticos de una comunidad de habla nábuatl de Puebla. México: INI.

Taggart, J. M. 1983. Nabuat Myth and Social Structure. Austin: University of Texas Press.

Taggart, J. M. 1997. The Bear and His Sons: Masculinity in Spanish and Mexican Folktales. Austin: University of Texas Press.

Taggart, J. M. 2003. "Cómo los niños nahuas aprenden a ser adultos: inculcando el respeto hoy en día en una comunidad mexicana", Ponencia presentada en Cambios y contrastes. III Reunión del Grupo de Trabajo 'Familia e Infancia' del Consejo Latinoamericano de Ciencias Sociales, Valdivia, Chile, 29 de septiembre al 1 de octubre.

Fecha de recepción: 2 de octubre de 2010

Fecha de aceptación: 25 de mayo de 2012 